\title{
Transceptor de coste reducido basado en VCSEL para redes udWDM flexibles metropolitanas y de acceso
}

\author{
Jose A. Altabas ${ }^{1}$, D. Izquierdo ${ }^{1}$, Jose A. Lazaro ${ }^{2}$, I. Garces ${ }^{1}$ \\ ${ }^{1}$ Grupo de Tecnologías Fotónicas (GTF) \\ Instituto de Investigación en Ingeniería de Aragón (I3A) \\ Universidad de Zaragoza, Mariano Esquillor s/n, 50018, Zaragoza, Spain. \\ Tel.+34-976762707, e-mail:jaltabas@unizar.es \\ ${ }^{2}$ Universitat Politècnica de Catalunya, Jordi Girona 31, 08034, Barcelona, Spain
}

\begin{abstract}
En este artículo se presenta un transceptor de coste reducido para redes uDWDM que funciona a $1 \mathrm{Gbps}$ full-duplex. El componente principal del transceptor es un láser VCSEL que alimenta tanto al transmisor basado en un RSOA modulado en fase como al receptor coherente que utiliza este VCSEL como Oscilador Local.
\end{abstract}

\section{Introducción}

Las nuevas redes de acceso y metropolitanas están evolucionando continuamente para poder cumplir los nuevos requerimientos provenientes de los nuevos servicios en red, del Internet de las Cosas (IoT) y de la convergencia entre las redes ópticas y móviles en el marco de las futuras redes 5G [1]. Estos nuevos requerimientos están obligando al incremento de la complejidad de los transceptores en los terminales de los usuarios u Optical Network Units (ONU) sin un incremento significativo del coste de los mismos [2,3]. En este artículo, se presenta un transceptor (transmisor y receptor) de coste reducido para dichas ONUs para su uso en redes flexibles con multiplexación ultra densa en longitud de onda (uDWDM) [3].

\section{Transceptor}

Como elemento principal del transceptor se utiliza un láser VCSEL (Vertical Cavity Surface Emitting Lasers) de bajo coste que, como puede verse en la Fig. 1, alimenta tanto al transmisor como al receptor coherente del transceptor. La longitud de onda de emisión de este VSCEL puede ser ajustada en un rango de $5 \mathrm{~nm}$ para una potencia de emisión constante de $-1.5 \mathrm{dBm}$ (Fig. 2) pudiendo cambiar fácilmente el canal uDWDM de trabajo del transceptor.

\section{Transmisor}

El transmisor presentado en este artículo, Fig. 1, está basado en un RSOA (Reflective Semiconductor
Optical Amplifier) alimentado con parte de la emisión generada en el VCSEL [3]. La modulación que se consigue con el RSOA es una modulación de fase diferencial (DPSK Differential Phase Shift Keying) de 1 Gbps mediante pulsos rectangulares NRZ (Non-Return to Zero).

\section{Receptor}

El receptor del transceptor está basado en un receptor heterodino coherente que utiliza como oscilador local (LO) parte de la emisión del VCSEL. Gracias a esta técnica de detección coherente es posible sintonizar el canal a recibir además de mejorar la sensibilidad del sistema al amplificar la señal recibida con el oscilador local.

La combinación del transmisor y el receptor heterodino coherente basado en un único VCSEL permite sintonizar el canal full-duplex de forma conjunta ajustando únicamente la longitud de onda de este VCSEL como ya se ha comentado anteriormente.

En cuanto a la señal recibida por el transceptor, para la verificación del receptor se ha utilizado una modulación DPSK a $1 \mathrm{Gbps}$ usando un modulador Mach Zehnder (MZM) con pulsos Nyquist DPSK para asegurar la capacidad full-duplex en un canal uDWDM de 6.25GHz. En la Fig. 3.a, se presenta el espectro óptico del canal uDWDM con los dos sentidos de la comunicación full-duplex (DL Downlink y UL Uplink). Dicho espectro ha sido capturado con un High Resolution Complex Optical Spectrum Analyzer (HRCOSA) que también se ha utilizado para ajustar las modulaciones de fase mediante los diagramas de ojo de fase óptica (Fig. 3.b-c) y reducir los posibles residuos de modulación en amplitud mediante los diagramas IQ ópticos (Fig. 3.d-e). 


\section{Conclusiones}

En este artículo se ha presentado un transceptor coherente full-duplex a $1 \mathrm{Gbps}$ basado en un único VCSEL que sirve como alimentación óptica del RSOA utilizado como modulador directo de fase y como LO del receptor heterodino coherente. Este transceptor permite la comunicación full-duplex de $1 \mathrm{Gbps}$ en canales de $6.25 \mathrm{GHz}$ perfectamente adaptados para comunicaciones uDWDM en redes metropolitanas y de acceso. Finalmente, este transceptor introduce un grado de flexibilidad en la red, permitiendo el reposicionamiento de los usuarios en términos espectrales, simplemente variando la longitud de onda del VCSEL.

\section{REFERENCIAS}

[1]. FIORANI, M., MONTI, P., SKUBIC, B., MARTENSSON, J., VALCARENGHI, L., CASTOLDI, P., y WOSINSKA, L. Challenges for 5G transport networks. Proceedings of IEEE International Conference on Advanced Networks and Telecommuncations Systems (ANTS). New Delhi, India, 2014

[2]. ALTABAS, J.A., IZQUIERDO, D., LAZARO, J.A., LERIN, A., SOTELO, F., y GARCES. I. 1Gbps fullduplex links for ultra-dense-WDM $6.25 \mathrm{GHz}$ frequency slots in optical metro-access networks. Optics Express. 2016, no. 24, pp. 555-565.

[3]. ALTABAS, J.A., IZQUIERDO, D., LAZARO, J.A., y GARCES, I. Cost-Effective Transceiver Based on an RSOA and a VCSEL for Flexible uDWDM Networks. Photonics Technology Letter. 2016 no, 28(10), pp. 1111-1114.

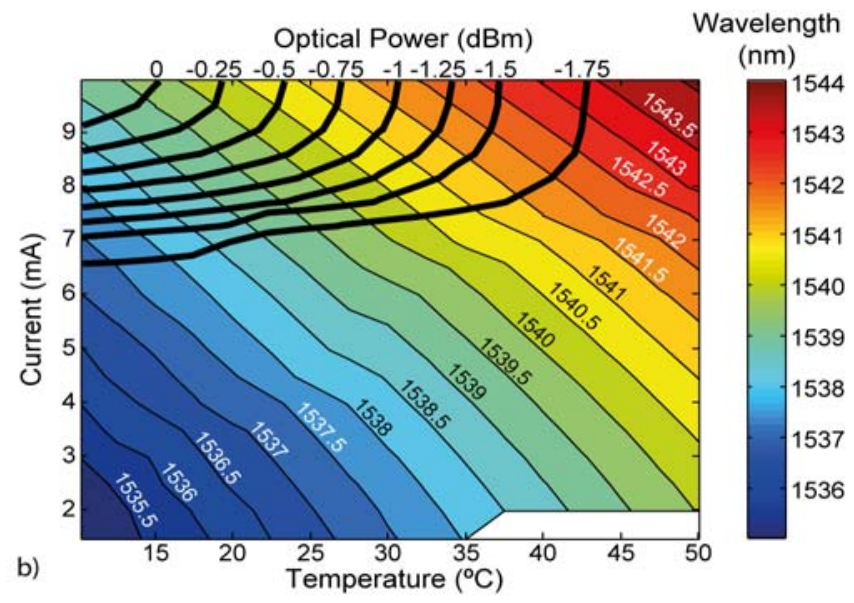

Fig. 2. Mapa de longitud de onda de emisión del VCSEL y potencia óptica constante en función de la corriente de alimentación y la temperatura de operación.

Fig. 1. Esquema del transceptor de ONU basado en un VCSEL.
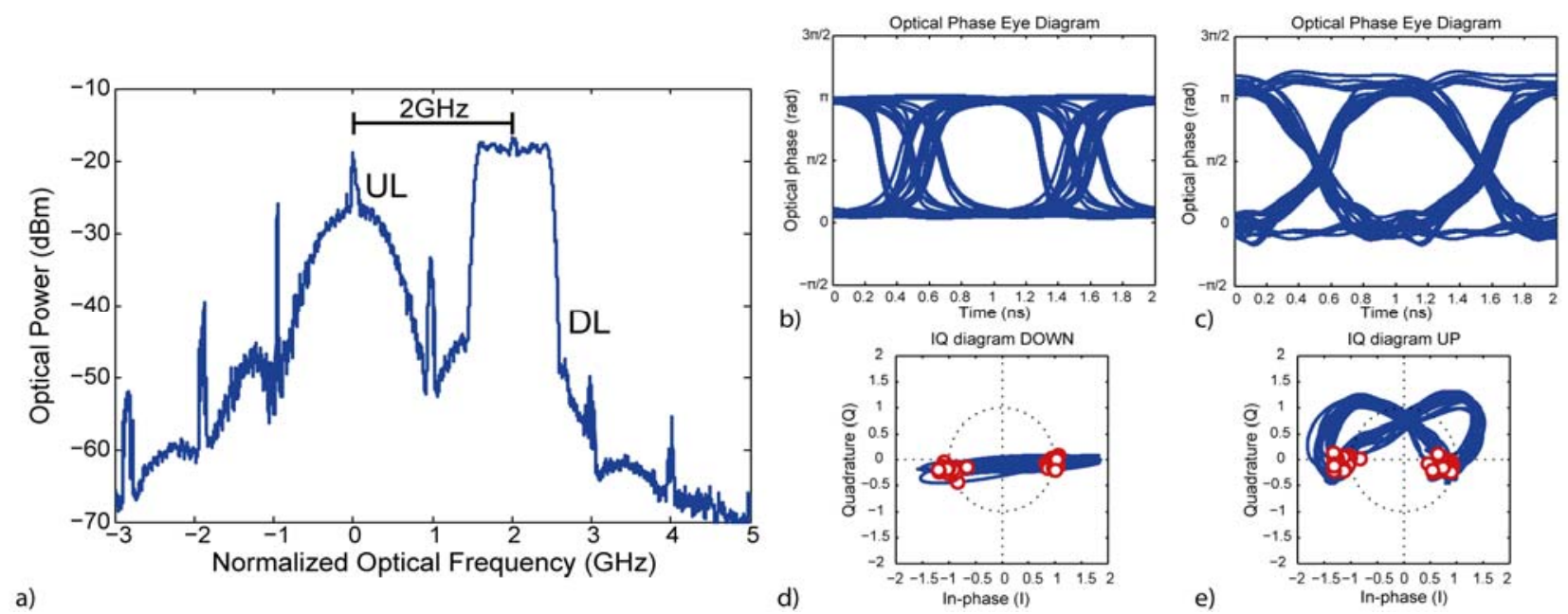

e)

Fig. 3. (a) Espectro óptico de canal uDWDM propuesto. (b) y (c) Diagramas de ojo de fase óptica, (d) y (e) diagrama IQ óptico. (b) y (d) son del enlace de subida. (c) y (e) son del enlace de bajada. 